observed. From none could there be elicited aught but negative history, either immediate or remote. All of the subjects are in excellent health. The men are moderate drinkers, and smokers; but few of them have had visual disturbance, and in these cases the trouble was due to some minor refractive error. Rarely in these cases have I found anisometropia which may occasionally be the cause of anisocoria. Pupils reacted consensually, also responded normally to light; convergence and accommodation in all cases except Nos. 6 and $9 ;$ the departure from normal in these cases consists in the peculiar reaction first described, I believe, by Gowers, as follows: "Immediately upon exposure to the light the pupils contract; light stimulus being continued, the abnormally dilated pupils rapidly regain their former size."

In all cases that I have had the opportunity of observing frequently, I find that there are times when the pupils are of equal size. The exacerbations can not be associated with excesses of any kind. In about one-half the cases seen the right pupil was the larger, while in the remainder the reverse obtained. The difference in size ranged from one-fourth to threefourths times larger than the smaller pupil. Incidentally I may mention that I have seen the same condition of unequal dilatation in dogs. Paresis or paralysis of the fibers of the oculo-motor nerve supplying the sphincter of the iris, irritation of the cilio-spinal center of the cervical spinal cord or the cervical sympathetic supplying the radiating fibers of the iris will produce dilatation of the pupil. As long as the third nerve functions properly, presupposing the optic nerve and retina to be intact, the reaction to convergence and accommodation will be normal. The accommodation unimpaired, with normal reaction of the pupils to convergence and accommodation, I think it safe to conclude that the unilateral mydriasis is not associated with impaired function of the third nerve, hence we naturally look to the sympathetic system for the cause of the abnormality.

The idea is quite general that there is a condition of enervation in persons residing in Leadville or at a like altitude. Knowing of this impression, I have employed the best means at my command to learn the truth or falsity of it. I find that the physicians of that district, almost with one accord, believe that the conditions dependent upon altitude cause innervation rather than enervation. The laboring men interrogated upon the subject bear out this opinion. Fifty miners, taken at random, being asked as to their general feeling of well being and their ability to do work as compared with a lesser altitude, forty-five of them thought they could do the same amount of work with greater willingness and less fatigue after having accomplished it than at a lesser altitude, while five believed the reverse. It should be stated, however, that the five last mentioned experienced difficulty in breathing. Most people coming from sea level to an altitude of 10,250 feet, become exceedingly short of breath upon slight exertion, and may have tinnitus aurium and a feeling of giddiness, because they are accustomed to breathing a much denser atmosphere and their lungs are not equal to the task of obtaining the requisite amount of oxygen from the rarefied air, and for a time there is enervation. If the lungs are healthy, a residence in Leadville will soon bring about a compensatory increase of lung capacity. This, with increased circulation of the blood, enables one to obtain all the oxygen required and he will no longer be bandicapped by dyspnea. When the lungs and circulation shall have adjusted themselves to the conditions, the depressed feeling he first experienced is supplanted by one of exhilaration.

The atmosphere being practically devoid of dust particles and moisture, the light is very intense and we would naturally expect to find contracted rather than dilated pupils; but I find cases in which there is bilateral mydriasis, and this fact but serves to confirm me in my theory of the cause of the anisocoria, namely, that it is due to hyperactivity of the nervous system, which is especially manifest in the cervical sympathetic. I believe that this hyperactivity stimulates equally the radiating fibers of the irides to contract and I account for the unequal dilatation upon the hypothesis that there is a difference in density of the radiating muscular fibers, and it may be of the sphincters also, of the irides.

I further believe that this tendency to excessive dilatation of the pupils is common to those living at so great an altitude and that in cases in which we do not find the anomaly the power of inhibition is sufficient to overcome it.

Case 1.-J. C., age 50, bill poster, resided in Leadville eigh teen years. Right mydriasis.

Case 2.-T. C. W., age 25, mining man, lived here two years. Right mydriasis

Case 3.-H. T. B., druggist, age 25, resided here five years.

Right mydriasis.

Case 4.-J. H., age 53, lived here eighteen years. Right mydriasis.

Case 5.-C. H. M., age 30, civil engineer, resided here two years. Left mydriasis.

Case 6.-J. J. M., age 46, furniture dealer, resided here eigh teen years. Left mydriasis.

Case \%.-S. G., age 27, salesman, lived in Leadville three years. Left mydriasis.

Case 8.-T. J. W., age 32, physician, resided here two years. Left mydriasis.

Case 9. - T. H., age 34, commission merchant, lived here eighteen years. Left mydriasis.

Case 10.-A. J. B., age 43 , saloon man, lived here five years. Left mydriasis.

Case 11.-J. S. B., age 40, mining man, resided here eigh teen years. Left mydriasis.

Case 12.-H. S. J., age 21, mining man, resided here one year, Left mydriasis.

Case 13.-C. H. B., age 24, dry goods merchant, lived here ten years. Right mydriasis.

Case 14.-Dr. A. J. McD., age 40, resided here seven years. Left mydriasis.

Case 15.-Ed. L., age 29, barber, lived in Leadville four years. Left mydriasis.

Case 16.-G., age 35, physician, resided here three years. Left mydriasis.

Case 17.-W. W. W., age 40, stationary engineer, resided in Leadville six years. Keft mydriasis.

Case 18.-B.. age 30, plumber, lived here four years. Left mydriasis.

Cuse 19.-D. A., age 28, telegraph operator, has lived in Leadville five years. Left mydriasis.

Case 20.-E. S., age 27, housewife, resided here six years. Right mydriasis.

\section{A SIMPLE, PAINLESS AND PERHAPS NEW METHOD OF VACCINATION; DENUDA- TION VERSUS SCARIFICATION.}

BY M. B. HUTCHINS, M.D.,

CLINICAL LECTURER ON DERMATOLOGY AND SYPHILOGRAPHY, ATIANTA MEDICAL COLLEGR, ATLANTA, Ga.

This method may fall under the category of "nothing new under the sun," but I have not been able to find that the simple principles followed have ever been put into practice before. The idea of perfecting 
a new method of preparing the skin for inoculation was brought to my mind because of my sympathy for little children who are frightened and even given pain by the old, scarification plan.

The protection from absorption possessed by the skin is due to the epidermis and chiefly to the horny layer. This being removed, or even scarified, permits absorption. An excoriation or denudation is necessary to local infection in most cases, though follicular inoculation has been credited. Given, then, an impermeable covering, it was but necessary to find an agent which would dissolve or disintegrate the upper layers of the epidermis without pain or fright to the patient. Salicylic acid in glycerin was tried and discarded. A saturated solution of caustic potash in a 20 per cent. solution of cocain was effective, though the final product of the mixture was uncertain. A light application of the caustic potash stick was tried, being neutralieed with acetic acid as soon as burning was felt. ${ }^{1}$ This was effective, but acted rather severely, and left some pigmentation from slight inflammation. Finally, ordinary liquor potassæ was tried and found to meet every indication.

The elder Hebra denuded his old eczema patches with green soap and rubbing, and this softening action of potassa has long been well known. We use liquor potassæ in mounting scales and hairs for microscopic examination, and it rapidly disintegrates them. The pigmentary deposits in the epidermis are easily remuved after the application of liquor potassæ. Officinal liquor potassæ is a 5 per cent. solution, that in common use becomes stronger through evaporation.

The procedure of preparing the surface for vaccination is as follows: The point to be vaccinated is cleansed. A piece of cotton as large as the desired denudation is wet with liquor potassæ and laid on, or a little of the fluid is put on with the bottle stopper. After two or three minutes, or as soon as sliight burning is felt--it usually does not burn at all-the cotton is removed, if it was used, the soap mixture which has formed with the skin secretions is wiped off with a piece of wet cotton, though this is not essential to success, in order to render the next step easier. Then an ink eraser, a tooth-pick of soft wood, a pencil rubber, a piece of gauze (the quickest) or a piece of damp cotton is used to rub away the softened epidermis. The friction is slight, the pain is only a little stinging when the sensory nerve filaments become exposed. We obtain in a few seconds a moist, shining surface, often a clear view of the papillary vessels but no bleeding. The vaccine is now applied and let dry on in the usual way.

The advantages of this method are its practical painlessness and the absence of terrifying instruments, such as the "Neptune's trident," the lancet or sewing needle. Further, bleeding is a bar to successful inoculation. By scarification it is difficult to stop short of bleeding, while with denudation bleeding is almost impossible. A little girl aged 6 years, vaccinated her. self by my method. There is also less danger of an undesired infection from instrument or epidermis when this method is employed.

As to the results: A good lymph will "take"; an unreliable one will not. Inoculation was successful in as many cases vaccinated by denudation as by scar-

Since writing the above the caustic potash stick was tried again, in the absence of a supply of liquor potassa. A minute drop of the delicuescing potash was put on, gently smoothed out and immedi the pain nil and the procedure even more rapid than scarification. ification. Within three days one young man developed twenty-five distinct and characteristic vesicles in an area three-fourths of an inch square. Others "took" in the usual way. Abortive lesions formed in other cases just as after the old method.

One doctor vaccinated seven children in an institution at his first trial of my method. With three he did not wash off the liquor potassæ before denuding; in four he did. Every one of the seven "took." The doctor was fortunate in his lymph. Other physicians have found the method successful. Many cases could not be followed up. Increased experience with the method and the reports of others demonstrate probably a larger percentage of success than is possible with scarification.

Ordinarily there may be one objection to the method of denudation; it is alower, but the time necessary to subdue a refractory child for scarification will often amount to more than two or three minutes. Again, if we draw blood in scarifying, this must all be removed and further flow checked to insure a result; this takes time. For those who wish to save themselves annoyance, or to spare little children and nervous people pain and fright, the method described is preferable. Sympathy and convenience justify its use even if the whole matter is simple and small.

Denudation offers a field for dermic medication which may reduce the necessity for so much use of the hypodermic syringe. I have not experimented here except with cocain and eucain solutions. I obtained their characteristic effects. Something similar to this has been used for the dermic absorption of drugs, viz., the formation of a blister which resulted in the denudation of an absorbent surface. A denudation maintained with moist rubber tissue might spare some ill person frequent, painful thrusts of the hypodermic needle, where such introduction of drugs should be practiced.

Note.--This method was demonstrated to the A tlanta Society of Medicine on the evening of Sept. 21, 1897, a report of which will be published. Most of the experiments with the method were made since September 1 of this year, although slight trial of other agents was had some months ago.

311-312 Fitten Building.

\section{THE DRY METHOD IN INTRA-UTERINE SURGERY.}

Read before the Illinois State Medical Society. BY EDWIN WALKFR, M.D., PH.D.

EVANSVYLIE, IND.

Last year I read before this society a paper on the abuse of water in surgery (AMERICAN MEdical Association Journal, No. 26, 1896). Some of the disadvantages of its excessive use in both septic and aseptic cases was pointed out. It was urged also, that outside of hospitals, where we have to rely on unskilled. help to prepare the water, it is often used from vessels. improperly cared for, and is often the source of infec. tion. On the other hand, there is no longer a doubt. that ideal asepsis may be attained by the dry method. The action of the water, though it be pure and sterile, exercises an unfavorable influence on healthy tissues, while antiseptic solutions often injure them and mark. edly reduce their ability to resist infection. It is practically settled, that septic wounds can not be rendered aseptic by any washing, or the use of antiseptics, no matter how strong they are used; all we can do is to render the conditions such as to give the tissues a chance to exclude the germs. 